\title{
PLÁGIO E AUTOPLÁGIO: DESENCONTROS AUTORAIS
}

\author{
Maria Marta Furlanetto* \\ Fábio José Rauen** \\ Silvânia Siebert*** \\ Universidade do Sul de Santa Catarina \\ Programa de Pós-graduação em Ciências da Linguagem \\ Tubarão, SC, Brasil
}

\begin{abstract}
"Repetição e deslocamento. Paráfrase e metáfora. Às margens do texto, textos fantasmas diluem as bordas da textualização, seus limites."
\end{abstract}

(Eni P. Orlandi)

\begin{abstract}
"Para onde vão os cientistas e a ciência? O destino não é conhecido, mas eles estão indo cada vez mais rápido."
\end{abstract}

(Thomaz Wood Jr.)

Para darmos parcialmente conta de implicações geradas pela discussão que promovemos em nossa edição 2017-3, propomos mais um episódio sobre a temática em curso, que integra subjetividade, alteridade e autoria, necessária porque nos afeta diretamente. Nesta edição elegemos como fio condutor o plágio e o autoplágio, considerados por editores como um dos grandes problemas para a divulgação científica no momento. Nos situamos como enunciadores em um processo de publicação científica, como revista especializada das áreas de Letras e Linguística - mais diretamente interessada em movimentos textuais e discursivos. Nesse modo de produção e divulgação participam autores, consultores, editores e o leitores especializados de ciência. Não há, em princípio, como pensarmos que exista falta de conhecimento sobre o funcionamento discursivo deste campo por parte dos sujeitos; poderíamos descartar, então - ao menos em grande parte -, a ingenuidade como argumento para a realização do plágio e do autoplágio.

\footnotetext{
* Doutora em Linguística Aplicada pela Université Paris VIII. Docente do Programa de Pós-graduação em Ciências da Linguagem da Universidade do Sul de Santa Catarina. Editora de Linguagem em (Dis)curso. E-mail: mmartafurlanetto@gmail.com.

** Doutor em Letras/Linguística pela Universidade Federal de Santa Catarina. Docente e Coordenador do Programa de Pós-graduação em Ciências da Linguagem da Universidade do Sul de Santa Catarina. Editor de Linguagem em (Dis)curso. E-mail: fabio.rauen@unisul.br.

*** Doutora em Linguística Aplicada pela Universidade Estadual de Campinas. Docente do Programa de Pós-graduação em Ciências da Linguagem da Universidade do Sul de Santa Catarina. Editora de Linguagem em (Dis)curso. E-mail: silvania@ cinemaistv.com.br.
} 
Estudiosos do tema confrontam o plágio e o autoplágio com a originalidade, a autoria, a propriedade, a moral, entre outras possibilidades. O plágio enamora-se da cópia, da paráfrase, da não citação, da omissão a outrem. É tomado como crime, como falta de conduta, quando pensado a partir do funcionamento jurídico, como abordado no e-book Plágio acadêmico (WACHOWICZ; COSTA, 2016).

A autoria, como destacamos na edição anterior, não é para nós, neste espaço, apenas um dos temas possíveis (e sempre revisitado): surge como uma figura sobrevoando o regime da prática autoral em trabalho científico - o universo de saberes em construção. Nesse processo, o fantasma do plágio e do autoplágio nos assombra. A forma aparentemente "inócua" (digamos assim), mas não sem consequência, é aquela que corresponde à citação desabrida, em que se abandona o esforço de pensamento original para convidar os autores consultados ao palco do texto. E não vamos nos remeter diretamente a outros problemas, como o da coautoria em níveis diversos, inclusive o do relacionamento, na academia, entre orientadores e seus estudantes ${ }^{1}$.

Nesta edição, buscamos pensar a partir do estudos do discurso. Seguindo Orlandi, assumimos que "do ponto de vista de suas condições de produção, o texto tem relação com a situação e com outros textos, o que lhe dá um caráter não acabado." (2001a, p. 181). Ele tem, portanto, limites difusos, em função de se apresentar como materialidade linguístico-histórica da discursividade. Seu acabamento, por força do trabalho autoral (função-autor) em busca de unidade, é da ordem do imaginário: "Se a discursividade é incomensurável em seu real, o texto representa imaginariamente o dizer como uma extensão com limites, pausas, beiradas (bordas) possíveis. E o autor se representa como responsável na origem do texto que produz." (ORLANDI, 2001b, p. 93). Porém, o resultado é sempre precário, sempre passível de textualizações que rodeiam suas bordas: versões, variantes, paráfrases, em jogo em duas direções: para a repetição e para o deslocamento, o que corresponde a dois processos fundamentais da dinâmica da linguagem propostos por Orlandi (cf. 2001a, p. 137): a paráfrase e a polissemia - em sentido amplo, abarcando o funcionamento geral, não um episódio particular e local.

É a partir desta divisão em termos de movimento que Orlandi (2001a) distingue produtividade e criatividade no trabalho com linguagem. A paráfrase remete a determinado espaço do que é dizível; repete, mantém-se no mesmo, entendido como uma matriz, um acervo memorial reconhecido. Isso seria produtividade nesta perspectiva. A polissemia representa o deslocamento, a abertura e a possibilidade de ruptura: remete à criatividade. Os dois movimentos de força vivem em tensão na linguagem. Dado esse jogo no funcionamento textual-discursivo, Orlandi acaba por estabelecer esta sentença memorável: "Ao longo de toda uma vida não é talvez senão o mesmo texto que trabalhamos incessantemente, acrescentando, transformando, repetindo, à busca de sua forma mais acabada." (2001b, p. 95-96). Nesse trabalho incessante, nunca encontraremos a última palavra. A aparência que ela possa tomar apenas indicia novo deslizamento em nosso histórico de produção.

\footnotetext{
${ }^{1}$ Sobre esse tema, Targino (2010) nos oferece uma visão esclarecedora em Orientador ou tutor é autor?.
} 
As condições de produção da ciência nos remetem ao termo produtividade, que reivindica a repetição para atender ao princípio de fazer muito em pouco tempo. Afinal, os pesquisadores são cobrados em ter publicações inéditas, textos novos em um ritmo de dedicação exclusiva à produção da escrita do trabalho científico. No entanto, este mesmo pesquisador precisa orientar, lecionar, pesquisar... Esta pressão pela produtividade desenha um cenário difícil para as revistas científicas, que cada vez mais vêm recebendo artigos com plágio e autoplágio - modalidades distintas em termos de processos autorais política e juridicamente considerados, mas ambas fazendo o movimento entre paráfrase e polissemia, entre produtividade e criatividade, segundo a concepção discursiva.

O autoplágio não é perspectivado como crime; no entanto, tem sido encarado como conduta pouco ética em função de fatores políticos, culturais e morais. Dada a expansão desse modo de refletir sobre a divulgação de trabalhos científicos, tem proliferado a produção de artefatos para identificação das experiências consideradas pouco éticas na produção e divulgação de trabalhos nas mais diversas áreas do conhecimento, como temos lido em inúmeros materiais que divulgam o problema e fornecem meios de detecção que ajudem a coibir tais atitudes - indício claro de que algo nada subterrâneo está estimulando essas experiências - e, em o fazendo, vêm causando constrangimento e exigindo reflexão e atitude: o tema prolifera em ambiente às vezes nebuloso, provocativo. Isso tem levado editores a estabelecer normas específicas para a publicação e mesmo exigir o compromisso de que os trabalhos submetidos são originais, inéditos e sem duplicação de publicação - como é o caso de nosso periódico. Subsequentemente, nos damos conta de que mais um problema deve merecer nossa atenção: aquele de como os enunciados podem ser lidos - portanto, um aparente detalhe sobre como o discurso funciona.

Isto conduz, de início, a pensar em como podemos ou devemos julgar a exigência de produtividade - que nos dá pontos em avaliação ou nos sonega esses pontos por falha de produção (ausência ou insuficiência). Por que produtividade?

É senso comum vincular produtividade, de imediato, ao espaço econômico e empresarial, em rede mais ampla com política, visto que o crescimento de um país está associado aos negócios de produção e produtividade, que presumem, então, planejamento, eficiência e rentabilidade. É preciso ser capaz de produzir mais com menos (menos esforço - mão de obra -, menos recursos - equipamentos -, menos tempo, e com apoio logístico apropriado: resultados científicos). Temos aí o que se chama otimização - ou ainda: a relação equilibrada entre custo e benefício. Na ponta desse processo, o imaginário do espaço político-econômico prevê o que se deseja: mercado amplo, melhores salários, melhor padrão de vida, mais consumo, tudo voltado para o trabalhador, para os consumidores e ... para o capital.

A produtividade, idealmente (imaginariamente), presume a busca de aperfeiçoamento, inovação, resultados qualitativos, indo na direção do crescimento - para a empresa, para o estado e o país, em última análise. O conceito, portanto, no plano da Economia, vincula-se à noção de capacidade de produção com menos meios e menos tempo, devendo resultar em mais lucro e mais crescimento. Resulta daí que ele apresenta uma aura positiva econômica e socialmente falando, porque levaria ao bem-estar social (uma espécie de memória do futuro). Era indispensável que, nessa equação, não houvesse esquecimento do mundo sociocultural. 
O conceito migrou para a área educacional e teve repercussão, por exemplo, na ampliação do Ensino Fundamental de oito para nove anos (mais tempo de ensino, mais aprendizagem) - o que educadores em geral têm interpretado como significando mais responsabilidades para os agentes educacionais, de par com o crescente controle de resultados (os inúmeros testes periódicos e as estatísticas proliferam). A mesma direção vimos, em 2016, no debate acirrado em torno da proposta da Base Nacional Comum Curricular (BNCC) que, pela unificação do currículo da educação básica, dizia-se voltada para o aprimoramento da educação brasileira, estabelecendo, direta ou indiretamente, o que seria qualidade na educação.

Mas como isso se reflete na produção científica? Aparentemente, publica-se muito, mas isso não redunda necessariamente em maior impacto ou crescente qualidade - e duas das falhas comumente apontadas é a da reprodução/redundância (variantes, versões parafrásticas) e a da salami slicing (fatiamento de salame) - ciência em fatias. Editores em geral têm bastante experiência com esses fenômenos na rotina de tramitação de trabalhos científicos: uma única pesquisa relativamente volumosa pode ser recortada em partes (capítulos ou não) e ser reapresentada como artigo ou ensaio sem manifestar propriamente ineditismo, renovação e progressão. Funciona mais diretamente como divulgação (como publicidade do que já está feito).

E (o que não pode ser desconsiderado) o volume de produção - de boa ou má qualidade, repetitiva ou original, presentificando no quadrante do mesmo (paráfrase) ou do diferente (polissemia), do autoplágio ou da originalidade - está, certamente, além da capacidade de qualquer bom leitor, capaz de refletir e cocriar, acompanhando o movimento dos autores, de uma única área de estudos que seja.

A injunção à produtividade em ciência, em todo caso, deixa na sombra outra noção que emparelha com ela: a competitividade. São ambas, como noções originadas na área econômica - e portanto não estranhas a nenhum campo ou esfera de nossa formação social -, suficientemente naturalizadas para, à primeira vista, não causar desconforto. Assim, em perspectiva ética, apreciemos esta constatação de Assmann (2009, p. 111): “cada vez mais somos empurrados para a produtividade e para a competição com os colegas. Ser competitivo tornou-se uma 'virtude'. E se o bem for bem apenas para mim, então competidor virtuoso e bom é quem consegue eliminar ou matar os outros competidores.". Pode ocorrer-nos - e não parece ser mera fantasia - que a exploração dos jogos eletrônicos, em vista da recepção que têm e a dominância em estimular a competição, são instrumentos para moldar corpos e mentes desde cedo para a sobrevivência em qualquer campo. Mas de que sobrevivência se trata? Sobrevivência soa de modo tão natural que funciona como argumento inelutável por si só.

Ao mesmo tempo, há que considerar a contradição que se afirma entre o mundo estrito do capital e o que ressoa em volta, em todas as esferas sociais, especificamente, no caso em pauta, no espaço da ciência: "Enquanto é o capital que precisa do conhecimento gerado pelos trabalhadores-pesquisadores para reproduzir-se, estes vivenciam a intensificação e alienação do seu trabalho; tal dependência aponta para o desafio de exercer seu poder." (MACHADO; BIANCHETTI, 2011, p. 244). Esta contradição não pode ser explicada senão considerando, no grande tempo, a formação das relações entre universidade, ciência, governos e economia, e os compromissos que foram sendo criados entre essas instâncias - resultantes de pequenos ou grandes eventos. É o 
que propõem Machado e Bianchetti, viajando ao passado para entender o mundo contemporâneo, suas figurações e seu rumo.

Nesse texto, já no título, os autores escolhem realizar um deslocamento: de produtividade para produtivismo, que certamente produz um sentido de ruptura com a tradição do setor econômico e fazendo diluir qualquer possibilidade de que os resultados de tal política possam gerar também a qualidade imaginada. Nessa direção declarada, exploram como foram construídas as relações entre universidade/ciência, economia e governos: como, por exemplo, um órgão governamental como a CAPES (Coordenadoria de Aperfeiçoamento do Pessoal de Nível Superior) começou a mediar os interesses surgidos dessa aproximação, transformando esses interesses em demandas que, de algum modo, estariam afinadas com sua meta de órgão estatal: o Aperfeiçoamento - de fato, algo como um deslocamento, na universidade, que a levava a trabalhar de modo não autônomo em função da tríade que se formou com a implementação dessa política: educação, ciência e tecnologia - política elaborada não em nível nacional, mas mundial. Da mesma forma que para a produtividade em nível estrito - produção orientada para aumento de bens de consumo e crescimento nacional - a educação se vê mergulhada nessa rede, que passa a ser conhecida como sociedade pós-industrial - concepção do sociólogo americano Daniel Bell, como mostram Machado e Bianchetti (2011).

Por um lado, o ingresso de financiamento para a formação em pesquisa não pode ser pensado de modo negativo: universidades precisam produzir conhecimento. Por outro, elas não podiam engendrar livremente suas próprias metas e meios: tornaram-se subservientes, vinculadas a um poder com mecanismos nem sempre explícitos para fins não necessariamente conhecidos, embora acenados e perfilados na forma de bem-estar social, aparentemente o futuro certo implicado pelo crescimento econômico. Enfim, mudanças históricas, econômicas, estatais e sociais não têm refletido substancialmente a situação das universidades e das instituições de pesquisa e divulgação de conhecimento, de modo que continuamos suportando o enredamento constituído por essas amarrações e interesses.

Dado que, como questionam Machado e Bianchetti (2011, p. 252), cabe saber "a quem legitimamente pertencem as descobertas e inovações decorrentes do trabalho dos pesquisadores", é responsabilidade de políticas públicas impedir que empresas se apropriem dos resultados dessa nova força de trabalho que são os pesquisadores, se, no final das contas, a pretensão política é o retorno à sociedade. Isso destacado, pode até soar estranho que, de par com a produtividade (produtivismo?), haja um movimento tão ferrenho de gerenciamento da produção autoral, de ataque ao plágio e, mais recentemente, ao autoplágio, se pusermos em luz suficientemente clara a dificuldade de filtrar, no volume de produção autoral, todas as variantes desses fenômenos - quando não a detecção de problemas mais graves. A luta pela produtividade (alimentada por bolsas, às vezes, que sinalizam o reconhecimento por parte dos setores de financiamento) não é necessariamente refletida na alta qualidade de uma produção - assim como a superprodução de mercadorias não é refletida no bem-estar social e no esmaecimento das diferenças e dos conflitos, como projetava o sociólogo Daniel Bell (que, aliás, reconheceu depois os conflitos resultantes do "capitalismo avançado").

Há formas, contudo, de confrontar o gerenciamento mercadológico da produção intelectual, e não poucos autores têm procurado contrastar a fast science (variedade científica do fast food que impregna as sociedades como decorrência da vida atribulada, 
que não tem agenda para os cuidados de si) com a slow science. Um exemplo é a discussão proposta por Zoppi Fontana $(2012)^{2}$, que analisa o funcionamento do discurso da produtividade científica no contexto do movimento da slow science. Com isso, trabalha formas de representação da temporalidade (visando à desaceleração) e procede a uma análise de material diferenciado sobre o tema, incluindo modos de circulação do conhecimento científico. Tecnologia, inovação, índices de impacto - eis o que informa a produtividade, em uma armação em que uma coisa leva inevitavelmente à outra, e assim se mede a ciência. São as condições de produção. A ciência circula, efetivamente, marcando toda a vida social, inclusive na forma da divulgação científica, saber distribuído para a população em geral. E aqui entra a questão principal: qual a relação entre a temporalidade da ciência e a temporalidade do social? Diz a autora: "os sentidos de novidade e de avanço se impõem como imagem dominante na representação social da ciência, deslegitimando aqueles campos de conhecimento cuja prática não produz 'descobertas'." (2012, p. 227).

Isso estabelecido, a pesquisa científica se pauta pela lógica do modo de produção capitalista. E essa lógica se espalha para todas as esferas e setores conhecidos. O que Zoppi Fontana persegue é saber se todas as áreas de conhecimento têm a mesma representação da temporalidade e se as eventuais diferenças afetam a imagem discursiva delas - dando foco à polêmica instaurada pelo movimento slow science - que se configura como uma resposta aos excessos da fast science. A slow science surge em manifestos de pesquisadores internacionais, replicando movimentos sociais e partilhando a preocupação com os vínculos entre tecnologia, ciência e sociedade. A autora, então, quer mostrar como, em certos lugares discursivos, são ressignificados os tempos da ciência; e, nessa representação, ver indícios de estar no mundo de sujeitos da ciência - o que leva a vislumbrar como se reorganiza, em cada caso, a memória discursiva.

Ora, as políticas de pesquisa contemporâneas manipulam um tempo de aceleração, e então "os enunciados narrativos sobre a ciência desenham espaços de identificação fortemente marcados por temporalidades lançadas para o futuro em ritmo crescente de aceleração" (ZOPPI FONTANA, 2012, p. 234, grifos da autora). Os manifestos da slow science (movimento iniciado pelo antropólogo francês Joël Candau), ao contrário, propugnavam Dar tempo ao tempo da Ciência (o slogan do movimento). À medida que esse movimento se propagava e criava, no caminho, outros espaços de convergência, o afrontamento se tornava mais visível, e um jogo de argumentos se pôs em atrito. Enunciados já naturalizados se repetiam como verdades sustentadas para rivalizar com a política da slow science: rapidez no fluxo de informações, meios adequados para a produção de pesquisas (efeito das tecnologias), portanto necessidade de disseminação rápida... Neste ponto a autora aponta a direção discursivo-ideológica que recolhe e ressignifica a memória do tempo da ciência: discursividade evolucionista (seleção dos mais fortes); discursividade positivista (progresso da ciência). Em confronto, trabalha a memória da ciência lenta, que produz conhecimento fundamental bem enraizado, que precisa ser protegido e retrabalhado com cuidado e tempo. (cf. ZOPPI FONTANA, 2012, p. 240-241).

\footnotetext{
${ }^{2}$ Professora do Instituto de Estudos da Linguagem da UNICAMP e bolsista de produtividade em pesquisa do $\mathrm{CNPq}$ ).
} 
Nessa análise e compreensão de processos de subjetivação relativamente ao tema desenvolvido - o fazer científico e o discurso de produtividade -, a autora remete a certas práticas institucionais que produzem mal-estar, como a divulgação, de tempos em tempos, de guias, códigos e manuais de boa conduta científica que nos chegam às mãos das agências estatais de gerenciamento da pesquisa científica. Ela expõe um recorte de documento que focaliza a prática do autoplágio - "indício dos efeitos do discurso da produtividade científica nos processos de subjetivação" (2012, p. 249). No caso, faz referência à fragmentação e reprodução de um trabalho para mostração de produtividade como "um gesto possível de resistência para não sucumbir" (2012, p. 250).

A autora manifesta, em seu texto, a necessidade de criar um espaço crítico para "quebrar as evidências que estancam o debate numa abordagem banalizada que penaliza os indivíduos, significando-os como causas e não efeitos dos processos históricos em curso." (p. 250).

Note-se, porém, que o recorte citado, de um documento de 2012 da FAPESP (fundação paulista de apoio à pesquisa), não tem a postura rígida que encontramos em documentos mais recentes. Citando um item: "Todo pesquisador que publicar trabalho científico idêntico, ou substancialmente semelhante, a trabalho já publicado deve mencionar expressa e destacadamente o fato no texto do trabalho." (apud ZOPPI FONTANA, 2012, p. 249). Supõe-se que a recepção do trabalho nestas condições passa a ser prerrogativa dos editores, consideradas as normas e restrições dos periódicos em questão.

Veja-se, porém, uma avaliação mais recente de agência à qual concerne o gerenciamento do problema, no caso a iThenticate (2011): “A American Psychological Association (APA), em suas instruções na edição de 2010, destaca que "the core of the new document must constitute an original contribution of knowledge, and only the amount of previously published material necessary to understand that contribution should be included, primarily in the discussion of theory and methodology.". Nesse white paper de 2011 aponta-se como o autoplágio passou a ser foco de discussão, considerando que autores podem entender que têm pleno direito de fazer uso de seus textos, copiando, parafraseando excertos ou integralmente. Na verdade, esse uso pode ferir leis de copyright e princípios de ética.

O autoplágio, tal como definido aí, é "a type of plagiarism in which the writer republishes a work in its entirely or reuses portions of a previously written text while authoring a new work." O problema que reside aí é, de início, apresentar um trabalho já publicado (em alguma instância, incluindo outro periódico) como se fosse original, novo. Por este aspecto pode-se entender o cuidado da FAPESP, no recorte visto acima, em fornecer a diretriz para não silenciar a editores e leitores a referência ao próprio trabalho. Se essa informação for suficiente para a aceitação do trabalho, não resta problema - salvo em caso de vínculo de copyright com a publicação anterior.

A retomada de porções de textos previamente escritos (monografias, dissertações, teses) para submissão a periódicos ou coletâneas tem sido uma forma de divulgação (em periódicos) relativamente aceita, tendo em vista o volume e a densidade desses trabalhos, que só leitores mais profundamente interessados visitam. Há ressalvas, porém, dependendo do periódico, cujas normas e restrições devem ser atendidas. Editores comumente deparam com pretensos artigos que têm a aparência de resumos malsucedidos 
em função da tentativa de tudo dizer sem chegar a um resultado consistente; ou que recortam porções e tentam articulá-las sem qualquer mudança significativa na retomada, constituindo às vezes cópia integral de parágrafos.

Se existe diferença gritante entre plágio e autoplágio, já que o primeiro implica delito relativamente a outro autor, que fica espoliado em seu direito, o autoplágio pode se apresentar com facetas que implicam menos ou mais problemas éticos, já que para a divulgação (publicação oficial) é imprescindível obter aceitação e, na maioria dos casos, por meio de avaliação criteriosa por pares. Há periódicos e periódicos, que, tratados segundo a lógica da produtividade incorporada pelas agências de gerenciamento da pesquisa científica, também são constrangidos a uma classificação, cujos critérios não cabe discutir aqui. De qualidade entendemos um pouco, vivendo de experiências de escrita, de circulação e de cuidado quanto ao que é esperado de nós, uma vez que não atingimos este ponto por mera imposição externa. O que justifica que, na posição de editores, esperamos dos autores mais do que assentimento ao produtivismo, que pode levar a resultados pouco ou nada originais, uma vez que temos de divulgar o que houver de melhor.

Enfim, há lugares para todas as experiências. A democracia na submissão não implica a aceitação de experiências de escrita que sejam exercícios de aprendizagem. Estes também têm seu lugar de divulgação, e todos os pesquisadores com experiência já tiveram uma longa fase de aprendizagem. A abertura que proporcionamos aos pesquisadores na Linguagem em (Dis)curso, ao deixar de exigir o título de doutor (porém dando preferência à titulação), acena apenas para a possibilidade de que não titulados possam realizar pesquisa relevante e explicitá-la adequadamente em materiais escritos.

Destaquemos três itens de nossas diretrizes:

Serão aceitas contribuições preferencialmente de pesquisadores doutores, não havendo, contudo, restrição de submissão para pesquisadores em geral, atendidas as condições e normas explicitadas aqui.

A revista publica artigos, ensaios, debates, retrospectivas (estado da arte) originais que contemplem pesquisa ou discussão teórica ainda não publicada, e resenhas. Desse modo, ao encaminhar o texto, o autor está automaticamente declarando que é inédito e que não o submeteu a outra publicação periódica ou coletânea. ${ }^{3}$

No caso de uma retomada (de texto publicado na Linguagem em (Dis)curso ou de outro periódico/obra) para revisão e/ou ampliação, essa condição deve estar explícita no texto e deve ser submetida aos editores, para verificação de sua pertinência.

Quando Zoppi Fontana (2012) manifesta, em seu texto, contrariedade à política de penalizar os pesquisadores pela exigência de produtividade, esquecendo que sofrem efeitos de processos históricos em curso, também destaca, em seguida: "Não se trata de fazer a apologia a uma ética da malandragem nem de negar a necessidade de uma regulação ética da pesquisa científica." (p. 250).

\footnotetext{
${ }^{3}$ Além dessa declaração automática, os autores devem incluir como documento suplementar um termo de responsabilidade com as assinaturas.
} 
Continuamos pensando na teia delicada que é tecida a partir do lugar da autoria, com os regimes autorais envolvendo formas subjetivas em alteridade, lendo, interpretando, retomando, produzindo, recriando - ensaiando a própria morte enquanto a escrita se prolonga para deixar cicatrizes do inacabamento. E tentando mais criar que repetir, já que repetir, embora necessário, não abre caminho. Apesar disso, mantém o caminho seguro, não o renega, não o apaga.

A permanente tensão de forças revisitada aqui continuará a ser discutida em outros episódios da Linguagem em (Dis)curso. Sem a polissemia, não teríamos material original; a originalidade reivindicada para os textos científicos, nós buscamos levar aos leitores desta edição, a par da discussão necessária. Trabalhamos com consultores especializados que nos ajudaram a organizar mais um número, e que se preocupam com a qualidade dos textos apresentados, com a originalidade na pesquisa científica em nossa área. A estes que nos acompanham dando assistência, nosso melhor agradecimento.

Que este episódio de reflexão remeta continuamente a nossas experiências de autoria nas edições da Linguagem em (Dis)curso, bem como às experiências de leitura, passo inevitável para construir a subjetividade autoral.

\section{REFERÊNCIAS}

ASSMANN, S. J. Filosofia e ética. Florianópolis: UFSC; Brasília: CAPES: UAB, 2009.

ITHENTICATE. Professional Plagiarism Prevention. The etics of self-plagiarism. 2011. Disponível em: <https://www.ithenticate.com/hs-fs/hub/92785/file-5414624-pdf/media/ith-selfplagiarismwhitepaper.pdf>. Acesso em: 5 fev. 2018.

MACHADO, A. M. N.; BIANCHETTI, L. (Des)fetichização do produtivismo acadêmico: desafios para o trabalhador-pesquisador. $R A E$, v. 15, n. 3, p. 244-254, maio/jun. 2011.

ORLANDI, E. A linguagem e seu funcionamento. Campinas: Editora Pontes, 2001a.

Discurso e texto: formulação e circulação dos sentidos. Campinas (SP): Editora Pontes, $2001 \mathrm{~b}$.

TARGINO, M. das G. Orientador ou tutor é autor? Informação \& Informação, Londrina, v. 15, n. esp., p. 145-156, 2010.

WACHOWICZ, M.; COSTA, J. A. F. Plágio acadêmico. Curitiba: Gedai Publicações, 2016.

WOOD Jr., T. Slow science. Carta Capital, 25 maio 2012 (Caderno Sociedade/Ciência).

ZOPPI FONTANA, M. G. Slow science: a temporalidade da ciência em ritmo de "impacto". Leitura, Maceió, n. 50, p. 223-257, jul./dez. 2012.

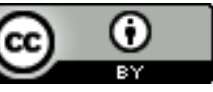

Este texto está licenciado com uma Licença Creative Commons Atribuição 4.0 Internacional. 